\title{
The emergence of nano risk-immunity
}

\author{
Steffen Foss Hansen* \\ DTU Environment, Technical University of Denmark, Denmark
}

\begin{abstract}
In 2010, a women developed nickel sensitization after having been weighing out nanoparticles. It is not the first time that concerns have been raised after human exposure to nanoparticles has caused serious adverse effects for these concerns to be dismissed shortly thereafter. The series of mysterious cancers among researchers in Lyon, the death of Chinese workers and the case of Nano Magic come to mind. All of these incidences are tragic. What is furthermore worrying is how fast experts in the field of nanotoxicology, industrial hygiene, and etc. refuted concerns about nanoparticles being the culprit based on very limited evidence. I would argue that the fact that these cases are happening is something to be very concerned about as such case reports combined with "authoritative assertions of safety" has historically been early indicators of widespread human and environmental harm. The lack of concern is an unhealthy symptom of "nanorisk-immunity" where we become more and more immune to news about risks of nanomaterials, the more incidents we hear about. Instead of refuting case reports as irrelevant, we should focus on what we can learn from history when it comes to emerging technologies.
\end{abstract}

\section{Introduction}

In 2010, a young women developed nickel sensitization after having been weighing out nickel nanoparticle powder and handled the particles on a lab bench with no protective measures. The incident was reported and documented by Journeay and Goldman in early May 2014 and the work had been published in the peer review journal of American journal of Industrial Medicine [1]. On paper, the incident seemed like a matter of serious concern and then not. Within a fortnight, Maynard [2] wrote an article in the daily web magazine, Slate titled "A new case study on the health risks of nanotech doesn't tell the whole story" arguing that "... the reported incident was more a case of bad exposure management than nanoparticle risk".

It is not the first time, that concerns has been raised after human exposure to nanoparticles have caused serious adverse effect for these concerns to be dismissed after a short period of time and reflection. The series of mysterious cancers among young researchers in a laboratory in Lyon [3] from 2014, the death of the Chinese workers from 2008 and the case of Nano Magic back in 2006 comes to mind.

Whatever the cause of the cancers, deaths and other ills, all of these incidences are tragic and concerning and it would have been good if they could have been avoided all together in the first place. What is furthermore worrying is how fast high-profile experts in the field of nanotoxicology, industrial hygiene, and etc. refuted concerns about nanoparticles being the culprit based on very limited evidence. In many cases this happened, just a few days or weeks after the incident was first reported in the popular media.

I am not saying that these experts are necessarily incorrect, but it is interesting to see how good we as a scientific community have become in explaining why reported adverse effects on nanomaterials published in the scientific peer-reviewed literature is not to be considered relevant and that we should not be that concerned about them. I would argue that the fact that these cases are happening and are being reported in the first place is something to be very concerned about as such case reports by scientists and reporting by individuals have historically been early indicators of a more solid evidence to emerge over the course of a couple of decades [4,5]. The fact that we are not more concerned about these incidents is an unhealthy sign of what I would call the development of "nanorisk-immunity" in our society. In this commentary, I will first trace the source of this nanorisk-immunity pointing out how early warnings on emerging risks tend to start with reporting of small case reports and authoritative assertions of safety.

\section{Mysterious cancers and deaths}

In July 2014, news stories emerged in France, in among other Le Figaro, reporting on the series of mysterious cancers and deaths among the scientific staff of Institut National Des Sciences Appliquées (INSA) located in Lyon, France [6,7].

Over the course of 13 years, 10 cases of cancers and deaths had been diagnosed among researcher aged 27-43 years in the Centre Lyonnais de Microscopie at INSA that works with the development and characterization of nanomaterials [8] and some speculated that this might be related to the advanced equipment used in microscopy in particularly, when it comes to nano-science and -technological research [3].

The discovery lead to the suspension of work at the microscopy center and the launch of an investigation into the potential leaks of ionizing radiation - something which later lead INSA management to dismiss the electron microscopes as being the cause of cancers detected among staff [8].

INSA management publically recognized that questions had been raised about a possible cause and effect relationship between cancers and the attendance of electron microscopy facilities, while simultaneously noting that some people have never used these facilities; that the cause of the cancers were unknown stressing that no link to occupation had

Correspondence to: Steffen Foss Hansen, DTU Environment, Technical University of Denmark, Kgs Lyngby, DK-2800, Denmark; E-mail: sfh@env.dtu.dk

Key words: early warnings, adverse effects, nanorisk-immunity, safety assertions, risk communication

Received: April 29, 2016; Accepted: May 17, 2016; Published: May 20, 2016 
been proven [6] and finally, that the cancer rates among laboratory staff was below the average statistical new cancers per year according to the regional health observatory [6].

\section{Death of Chinese workers}

A second case report on the adverse health effect of nanomaterials that made substantial internationals news was an incident that was investigated and described by Song et al. [9] and published in European Respiratory Journal. During the period of January and April, 20087 female young workers in a Chinese print plants were diagnosed with shortness of breath and excess of liquid in the lungs after exposure of cocktail of dust, fumes, and $\approx 30 \mathrm{~nm}$ polyacrylate nanoparticles for 5-13 months. All seven had been admitted to the hospital and eventually two of the women tragically died. Song et al. describes how the women had been working in 8-12 hours shifts in a 70 square meter room with no windows and no ventilation spraying a polyacrylic ester paste onto a polystyrene substrate that was subsequently heat-cured. Five months prior to the incidents the local exhaust ventilation in the facility had broke down and had not been prepared $[9,10]$. By transmission electron microscopy, nano particles were observed to lodge in the cytoplasm and caryoplasm of pulmonary epithelial and mesothelial cells, but also locate in the chest fluid. $\sim 30 \mathrm{~nm}$ diameter particles in fluid surrounding the lungs of the patients and in the cells lining inside and outside of the patients' lungs. Similar sized nanoparticles were found in the polyacrylic ester paste, and in the workplace ventilation system leading Song et al. [9] to conclude that their study might be the "...first study on the clinical toxicity in humans due to long-term exposure to nanoparticles..."

The study by Song et al. [9] raised a fair amount of critique among peers. Main areas of criticism focused on the lack of exposure data and that nothing concrete is known and reported about the nature of exposure (i.e. combination of fumes, dusts and nanoparticles) and magnitude and duration of the exposure. It was furthermore not described by Song et al. how the nanoparticles were produced and whether they were inhaled as single species or as large agglomerates or aggregates and for limited chemical analysis of the nanoparticles identified in the lung of the women $[11,12]$. Another point of criticism focused on the fact that there was no assessment of other plausible causes of the symptoms seen and that Song et al. quickly identified the nanoparticles as the culprit and one should be careful in extrapolating the conclusion from study into recommendations on handling of nanoparticles in general $[11,12]$. Some have argued that the study by Song et al. [9] should never have been published due this these deficiencies, whereas others have argued that this is not the main point of the paper, which is that appropriate workplace hygiene need to implemented in the nanotechnology industry as elsewhere in order to avoid preventable tragedies $[10,11]$.

\section{Nano magic}

The final case report worth mentioning here is related a protective glass and bathroom sealant known as "Nano Magic" that was recalled in Germany after more than a 100 consumers experienced severe breathing problems after using it in confined spaces [13-15]. In late March 2006, six people had to be hospitalized with water in the lungs. As in the case of Chinese death, the recall made the news headlines around the world. The product produced by Kleinmann GmbH was sold in a pump spray container in supermarkets and discount stores, but pulled from the market by the manufacturers after the Geman Federal Institute for Risk Assessment (BfR) had issued a product warning.
It later turned out that the product did not entail any nanoparticles. The manufacturer attributed the nanotechnological element of their product to the nanoscale layer of silicon dioxide that the product creates on surfaces $[16,17]$. One major element of controversy was that neither the German government nor the manufacturer knew what was in the product and whether appropriate safety testing had been performed. It eventually took the German Federal Institute for Risk Assessment (BfR) about two months to denounce the presence of nanoparticles in the product $[18,19]$. It was later speculated that the effects observed where due to the tiny droplets produced via the aerosol liquid spray and that enabled the solvent to penetrate deep into the lung. At the time the incident was seen as an early warning, a "wake-up" call for nanotechnology, and in hindsight it does seem that it led to a greater temporal focus on the potential health and environmental threats of this new technology [13].

\section{Starting small}

Commonalties across the case of the young women that developed nickel sensitization from Ni nanoparticles, the mysterious cancers and deaths in France, the incident with the Chinese workers as well as the case of Nano Magic are plenty. One denominator was that substantial concerns were raised in scientific or popular media after the reporting of individual case studies.

I would argue that the fact that these incidents are happening and are being reported in the first place is something to be very concerned about. Looking back at historical cases such as asbestos, benzene and lead in petrol, where we failed to adequately protect human health and the environment, the publication of individual case reports were a key early warning sign for emerging hazards that have yet to materialize themselves.

In the case of asbestos, Dr. Murray saw the first reported case of lung disease attributed to inhaled asbestos dust in a 33-year-old man in 1899. Similarly, a French factory inspector reported 50 deaths amongst female asbestos textile workers in 1906, but both reports were largely ignored. In 1924 the first inquest and pathological examination of an asbestos worker was performed on a worker that had died of asbestos poisoning and the pathologist Dr W. Cooke, wrote the case up in the medical literature [20].

Similarly, in the case of benzene, aplastic anaemia was first reported back in 1897 among young women engaged in the manufacture of bicycle tyres in Sweden, whereas hemorrhaging was observed in a young man engaged in a dry-cleaning operation in France. The association between benzene and leukaemia were first reported in 1928 by Dolore and Borgomano, who published a report on acute lymphatic leukaemia identified in a pharmaceutical worker. All of the reports were just a early signaling of the dramatically increase in reports of workers developing benzene related diseases of the bone marrow through the first half of the 20th century.

Finally, in the case of lead in petrol, the first reports about the adverse effects of lead in petrol were reported in the media after two years of production. At Standard Oil's Bayway labs in New Jersey in October 1924, five workers died and another 35 showed severe neurological symptoms of lead poisoning and the news media ran dramatic headlines about these death e.g. "Mad gas claims third victim" and "Bar Ethyl gas as fifth victim dies" [20].

\section{Authoritative assertions of safety}

Another common denominator between the different reports 
on adverse effects of nanomaterials is that high-profile experts and managers refuted them and seemed to downplay their relevance $[6,8,11,12,15]$ Again a number of historical parallels can be drawn as managers; CEOs of companies and other interested parties have repetitively been able to make authoritative assertions about the absence of risk despite having little or no evidence to support their assertions [20].

In response to the US Surgeon General asking General Motors, whether public health effects of lead had been taken into account, the reply was that "the average street will probably be so free from lead that it will be impossible to detect it or its absorption." [20]. Similarly, Standard Oil declared that "no perils existed in the use of this gas in automobiles", despite having no supportive evidence. Industry argued that the public was not at risk and that workers were only at risk due to their own "carelessness", or because they "worked too hard" [20].

Similarly, when press reports about the presence of PCBs in the environment and toxicity began to appear in the late 1960s, the producers stated that "This is simply not true" arguing that the source of PCB in the environment were unknown and calling for extensive research to confirm or deny the initial scientific conclusions [21].

Assertions of safety were also prevalent in case of mad cow disease where the Agriculture Minister in the UK told the House of Commons that there was "... clear scientific evidence that British beef is perfectly safe" [22]. In the case of asbestos, the current exposures to asbestos dust were considered to be so much lower than past exposures and therefore they were falsely assumed to be safe. When visiting a Canadian mine in 1952, the company doctor of Turner Brothers asbestos factory is on record for saying: "I am assured that many workers over 70 years of age are still employed and are active and vigorous" [20]. Finally, in the case of radiation, a degree of overconfidence existed in the medical fraternity regarding the use of X-rays and the theory was that the effects were caused by static electricity or individual sensitivity and not the interactions of the X-rays themselves. Some even totally denied the existence of X-ray effects [23].

\section{Lessons learned}

Substantial concerns have been raised in scientific or popular media after case reports on the adverse effects of nanomaterials after, which high-profile experts and managers have refuted these. As a consequence many have drawn a collective breath of relieve as serious -effects related to nanoparticles could potentially hamper the utilization of all the promised benefits of nanomaterials and put public acceptance of nanotechnology in jeopardy.

In historical cases such as asbestos, benzene, radiation, PCBs and lead in petrol, where we failed to adequately protect human health and the environment, individual case reports were a key early warning sign for emerging hazards that had yet to materialize themselves. Often, these reports were dismissed as being irrelevant just as the cases on nanomaterials are now, but it later turned out that we were just unable to pick up on the early warnings when they presented themselves due to our limited understanding of the nature of the risk at the time.

There are numerous examples of how discussions about risks of materials and substances were put to a halt by stakeholders, with an obvious conflict of interests, by using arguments such as the substances being essential to industrial progress; that all innovation entails risks; that the deaths and disabilities caused by the substance were due to the carelessness of the workers not taking precautions; and that there was no risk to the public due to different exposure conditions [20].
Similarly, highly respected scientists in the field of nanotoxicology, industrial hygiene, etc. have also repetitively downplayed concerns about risks of the nanomaterials using similar arguments.

I would argue that the fact that these individual cases are being reported in the first place and that we see this "authoritative assertion" of no risk is something to be very concerned about as such case studies by scientists and reporting by individuals have historically been early indicators of a more solid evidence to come $[4,5]$.

The fact that we are not more concerned about these incidents is an unhealthy sign of what I would call the development "nanoriskimmunity" in our society. Nanorisk-immunity is developed via exposure to nanorisk news on adverse health effects (that might be blown out of proportion) after which the news is subsequently downplayed by managers, experts and science journalists, whereby we become more and more indifferent and immune to news about the risks of nanomaterials, the more incidents we have and we hear about. The phenomenon is not something new as it is well known from risk perception research that people fell more familiar to what they perceive as known risks and then to underestimate these compared to unknown and less familiar risks $[24,25]$.

Instead of focusing so much on reports refusing this and that hazard related to nanomaterials, we should focus on what we can learn from history when it comes to emerging technologies. There are at least two lessons that we can learn about what we should not do and two lessons about what to do.

One key thing that we can learn is that we should not assume that "no evidence of harm" is the same as "evidence of no harm" when no relevant research is available to support authoritative assertion of safety. Instead we should be humble about early evidence indicating harm and accept that it might be flawed in the beginning as evidence of harm has historically tended to become stronger and stronger over time as scientific exploration and methods become more targeted and sophisticated.

Another key lesson learned from the past is not to dismiss evidence as irrelevant. Early evidence on lead poisoning came from the high exposures of fit, adult, but were perceived irrelevant due to the much lower exposures of the public to lead in petrol. It later turned out that the public in general and sub-groups (children, infants, etc.) in specific were more vulnerable to low doses of poisons [26].

When it comes to what we should do, the initiation of long-term research seems of vital importance. Early warnings on asbestos and lead in petrol were not followed up by long-term medical and exposure surveys of workers despite multiple recommendations to implement such activities and this had unfavorable consequences for public health. Long-term environmental and health monitoring rarely meets the short-term needs of anyone as noted by Gee and Greenberg [20]. Institutional arrangements, such as the creation of incentives and the allocation of funds, need to be put in place that provide independent long-term prospective monitoring of potential environmental health hazards.

A final lesson relates to ensuring interdisciplinarity into the research of hazards of nanomaterials. We need to make sure that views and input is taken from a wide range of all relevant disciplines and that specialists in one discipline (e.g. toxicology) are not allowed to express strong opinions about other disciplines as these have in the past gone largely unchallenged, and have contributed to misplaced complacency. This includes considering and following up on the views 
and experiences of victims, lay people and 'competent observers', such as factory inspectors and family doctors as these have historically anticipate the views of scientific experts, sometimes by many years [20].

\section{Acknowledgement}

This work is part of the project ENVNANO (Environmental Effects and Risk Evaluation of Engineered Nanoparticles) supported by the European Research Council (grant no. 281579).

\section{References}

1. Journeay WS, Goldman RH (2014) Occupational handling of nickel nanoparticles: a case report. Am J Ind Med 57: 1073-1076.[Crossref]

2. Maynard A (2014) Small Packages A new case study on the health risks of nanotech doesn't tell the whole story. [Online] Accessed on 20 October 2015.

3. Pièces et main d'Ouevre (2014) Epidémie de cancers à l'INSA de Lyon. [Online] Accessed on 20 October 2015.

4. European Environment Agency (2001)Late lessons from early warnings: the precautionary principle 1896-2000. Copenhagen: European Environment Agency.

5. European Environment Agency(2013). Late lessons from early warnings: Science, precaution and innovation. Copenhagen: European Environment Agency.

6. Sautot E (2014) Cancers à l'INSA : des cas de décès chez les chercheurs.[Online] Accessed on 20 October 2015.

7. Le Figaro avec AFP. Lyon: "épidémie de cancers" dans un labo. [Online] Accessed on 20 October 2015.

8. Sciences et Avenir avec AFP (2015) Une série de cancers mystérieuse dans un laboratoire lyonnais. [Online]Accessed on 20 October 2015.

9. Song Y, Li X, Du X (2009) Exposure to nanoparticles is related to pleural effusion, pulmonary fibrosis and granuloma. Eur Respir J 34: 559-567.[Crossref]

10. Maynard A (2009) New study seeks to link seven cases of occupational lung disease with nanoparticles and nanotechnology. [Online] Accessed on 20 October 2015.

11. Maynard A, Seaton A, Oberdörster G (2009) Nanoparticle exposure and occupational lung disease - six expert perspectives on a new clinical study.[Online]Accessed on 20 October 2015.
12. Brain JD, Kreyling W, Gehr P (2010) To the editors: express concern about the recent paper by Song et al. Eur Respir J 35: 226-227. [Crossref]

13. Maynard A (2006) "Magic Nano" Product Recall Update[Online]Accessed on 20 October 2015

14. Pauluhn J, Hahn A, Spielmann H (2008) Assessment of early acute lung injury in rats exposed to aerosols of consumer products: attempt to disentangle the "Magic Nano" conundrum. Inhal Toxicol 20: 1245-1262.[Crossref]

15. Glaza $\mathrm{P}(2010)$ Industry should take lead with media when an event like a recall occurs. [Online]Accessed on 20 October 2015.

16. Pescovitz D (2006) Magic Nano recall [Online]Accessed on 20 October 2015

17. Bulls K (2006) "Nano” Safety Recall.[Online] Accessed on 20 October 2015.

18. Elvin G (2006) No nano in Magic Nano. [Online] Accessed on 27 May 2006.

19. von Bubnoff A (2010) What's in a nano name? [Online] Accessed on 20 October 2015.

20. Gee D, Greenberg M (2001) Asbestos: from 'magic' to malevolent mineral. In: Harremoës et al., eds. Late lessons from early warnings: the precautionary principle 1896-2000. Copenhagen: European Environment Agency 52-63.

21. Koppe JG, Keys J (2001) PCBs and the precautionary principle. In: Harremoës et al., eds. Late lessons from early warnings: the precautionary principle 1896-2000. Copenhagen: European Environment Agency 64-75.

22. Zwanenberg Pv, Millstone E (2001) ‘Mad cow disease' 1980s-2000: how reassurances undermined precaution. In: Harremoës et al., eds. Late lessons from early warnings: the precautionary principle 1896-2000. Copenhagen: European Environment Agency $157-167$

23. Lambert B (2001) Radiation: early warnings; late effects. In: Harremoës et al., eds. Late lessons from early warnings: the precautionary principle 1896-2000. Copenhagen: European Environment Agency 31-37.

24. Kahneman D, Slovic P, Tversky A. Eds. (1982). Judgment Under Uncertainty: Heuristics and Biases. Cambridge: Cambridge University Press.

25. Kahneman D(2013)Thinking, Fast and Slow. New York: Farrar, Strauss, Giroux.

26. Needleman H, Gee D (2013) Lead in petrol 'makes the mind give way'. In Gee D et al., eds. Late lessons from early warnings: Science, precaution and innovation. Copenhagen: European Environment Agency 46-75.

Copyright: $(2016$ Hansen SF. This is an open-access article distributed under the terms of the Creative Commons Attribution License, which permits unrestricted use, distribution, and reproduction in any medium, provided the original author and source are credited. 